\title{
A CONSTRUÇÃO DO PROJETO POLÍTICO PEDAGÓGICO DA ESCOLA NA PERSPECTIVA DO ORIENTADOR EDUCACIONAL
}

\author{
THE CONSTRUCTION OF THE SCHOOL'S PEDAGOGICAL POLITICAL \\ PROJECT FROM THE PERSPECTIVE OF THE EDUCATIONAL GUIDELINE
}

\author{
Edineia Barros da Silva Campos ${ }^{1}$
}

\begin{abstract}
RESUMO: O presente estudo tem como finalidade refletir sobre o papel do Orientador Educacional no contexto atual com vistas à construção do Projeto Político Pedagógico na escola. Entende-se que o Projeto Político Pedagógico é um documento norteador das ações sócio - pedagógicas desenvolvidas na instituição educacional e que o mesmo deve ser o resultado de um trabalho de reflexão coletiva. Ressalta-se que este trabalho não tem a pretensão de trazer orientações quanto à elaboração do Projeto Político Pedagógico, visto que há um vasto número de documentos que normatizam tal prática, mas tecer algumas considerações sobre o mesmo, na perspectiva do Orientador Educacional, no que se refere a elaboração do Projeto Político Pedagógico nas escolas públicas. Essa pesquisa buscou fazer uma revisão bibliográfica, pretende-se por meio desta, trazer um breve resgate histórico da Orientação Educacional e a atuação desse profissional da educação na atualidade, bem como o seu papel na construção do Projeto Político Pedagógico, tendo em vista que o Orientador Educacional tem a função de articulador junto à comunidade escolar, colaborando para que ocorra a participação de todos os envolvidos no processo educativo na construção coletiva e democrática do projeto da escola.
\end{abstract}

Palavras - chave: Orientador Educacional. Projeto Político Pedagógico. Gestão democrática. Participação. Coletividade.

ABSTRACT: This study aims to reflect on the role of the Educational Advisor in the current context with a view to the construction of the Political Pedagogical Project at school. It is understood that the PPP is a guiding document for the socio - pedagogical actions developed in the educational institution and that it must be the result of a collective reflection work. It is noteworthy that this work does not intend to provide guidance regarding the preparation of the Political Pedagogical Project, since there are a vast number of documents that standardize such practice, but to make some considerations about it, from the perspective of the Educational Advisor, refers to the elaboration of the Political Pedagogical Project in public schools. This research sought to make a bibliographic review, it is intended, through this, to bring a brief historical recovery of Educational Guidance and the performance of this education professional today, as well as his role in the construction of the Pedagogical Political Project, considering that the Educational Advisor has the function of

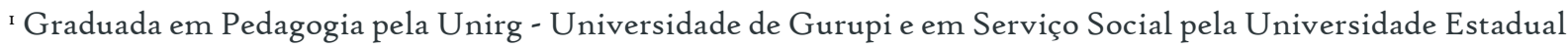
do Tocantins - UNITINS. Especialista em Gestão do Trabalho Pedagógico - Orientação Educacional pelo Centro Universitário Internacional - UNINTER. Atualmente é servidora no Instituto Federal do Tocantins - IFTO, atuando como Pedagoga no Serviço de Orientação Educacional. E-mail: edineia.silva@ifto.edu.br.
} 
articulating with the school community, collaborating so that the participation of all those involved in the educational process in the collective and democratic construction of the school project occurs.

Keywords: Educational Advisor. Pedagogical Political Project. Democratic management. Participation. Collectivity.

\section{INTRODUÇÃO}

O Orientador Educacional é um profissional da educação que atua junto ao processo pedagógico, colaborando com o aluno na formação de sua cidadania e na organização do trabalho escolar. No entanto, essa nem sempre foi sua atuação, pois pode-se observar que o início de trajetória desse profissional no Brasil foi caracterizado pelos aspectos individualistas, dando ênfase a abordagem psicológica, em que se privilegiava os "testes psicológicos" e o encaminhamento das questões de maneira preventiva, trabalhando com "alunos-problema", tentando ajustar estes à sociedade. Atualmente, o Orientador Educacional busca compreender a sociedade em que se insere o aluno, interpretar a relação escola e sociedade, com a finalidade de trabalhar de maneira contextualizada, envolvido com o cotidiano da escola, dos seus alunos e de suas representações. A Orientação Educacional parte, portanto, de um trabalho voltado à individualização para, uma atuação voltada à coletividade e a participação, comprometida com a formação do cidadão. Conforme Grinspun (200I), a Orientação Educacional, na atualidade, segue na busca da totalidade do aluno, com o foco na ampliação do conhecimento desse aluno enquanto pessoa, construindo sua personalidade e participando e forma consciente e ativa da sua história de vida, buscando valorizar a realidade desse educando.

Considerando o novo panorama de atuação do Orientador Educacional nas unidades escolares, pretende-se por meio deste estudo analisar o papel deste, enquanto articulador junto à comunidade escolar, na construção do Projeto Político Pedagógico, colaborando para a efetivação da gestão democrática nas escolas públicas.

Metodologicamente o estudo caracteriza-se como descritivo exploratório e se apoia numa base teórica consistente por meio da metodologia de abordagem bibliográfica, constituída pela análise de textos publicados, tanto na literatura especializada, como em periódicos (impressos e/ou disponibilizados na Internet).

O artigo foi organizado em itens. O primeiro apresenta a introdução, onde será abordado o tema no seu aspecto mais geral. O segundo apresenta o Desenvolvimento do estudo, no qual se faz um resgate histórico da Orientação Educacional e as mudanças significativas na atuação desse profissional, como também busca-se entender como se dá o processe de construção do Projeto 
Pedagógico na escol. E por fim, o item correspondente as considerações finais, nas quais se apresenta os argumentos mais relevantes considerados pela autora, no entendimento do papel do Orientador Educacional na construção do Projeto Político Pedagógico.

\section{Breve histórico da Orientação Educacional}

Para melhor compreender o papel do Orientador Educacional no contexto atual, faz-se necessário um breve resgate histórico da constituição desse profissional da educação.

De acordo com Almeida e Soares (2010), a Orientação Educacional tem sua origem em uma sociedade capitalista composta por classes sociais, na qual o orientador tem a finalidade de contribuir com o ajustamento dos indivíduos à ordem social vigente. Com a expansão do modo de produção capitalista e a produção em larga escala, houve a necessidade de se selecionar pessoas com características específicas para o desempenho de determinada função, surge assim, em meados de 1930, nos EUA, a figura do orientador profissional, com a finalidade de "medir" a capacidade dos indivíduos para o engajamento no mercado de trabalho.

Esse profissional que antes atuava nas empresas passa a atuar na instituição escolar com a visão de Orientação Vocacional, a fim de "aconselhar" os alunos direcionando-os ao mercado de trabalho de forma adequada e conformada.

No Brasil, as primeiras experiências em Orientação Educacional, aconteceram em 1924, em São Paulo, no Liceu de Artes e Ofícios, com os trabalhos do engenheiro suíço Roberto Mange. Pretendia ser um serviço de seleção e de orientação profissional para alunos do curso de mecânica. Mas foi na Lei Orgânica do Ensino Industrial, em 1942, que, pela primeira vez, fez-se referência à Orientação Educacional. Ela teria claramente um papel adaptador, o orientador poderia ser considerado um "ajustador", isto é, cabia a ele ajustar o aluno à escola, à família e à sociedade, a partir de parâmetros eleitos por essas instituições como sendo os de desempenhos satisfatórios (GRINSPUN, 20II, p. 28).

Em 1961, a Lei de Diretrizes e Bases da Educação Nacional confirma a referência à Orientação Educacional como ação educativa no ensino médio. Refere-se à criação da orientação educacional e vocacional, em cooperação com a família.

Em 1968, através da Lei n. 5.564/68, que regulamenta o exercício da profissão de orientador, deu ênfase a Orientação, tendo esta o objetivo de contribuir para o "desenvolvimento integral da personalidade do aluno", caracterizada por uma linha psicológica e preventiva.

Já com a Lei n. 5.692/71, a Orientação foi instituída obrigatoriamente nos estabelecimentos de ensino de $\mathrm{I}^{\mathrm{O}}$ e $2^{\mathrm{O}}$ graus, reforçando o ensino profissionalizante, através do aconselhamento 
vocacional, para a escolha de uma profissão futura de acordo com as necessidades do mercado de trabalho.

O Decreto n. 72.846/73, que determina as atribuições do Orientador Educacional, confirma o caráter psicológico da Orientação, em uma visão individualizada e pessoal, em que predominava o aconselhamento psicológico.

Já a década de 80 foi considerada um marco na história do país, onde se busca entender e questionar o sistema vigente. Dentre essas discussões a Escola começa a ser questionada quanto a seus objetivos e propósitos, pois esta se apresenta como reprodutora do sistema social. A partir desses questionamentos a classe começa a buscar uma identidade para o orientador, assim como um referencial que atendesse as suas reais necessidades, dentro de um contexto mais democrático que o país começava a vislumbrar. O orientador que atuava como "terapeuta" que atendia os alunos problema, começa a percebê-lo como um sujeito histórico, crítico e social.

Os eventos mais significativos para os orientadores educacionais se apresentaram na década de 8o, uma profissão que foi regulamentada em 1968, “cujos eventos promovidos vieram demonstrando um movimento de afirmação e negação de seus pressupostos básicos" (GRINSPUN, 20II, p. 32). Os orientadores começam a fazer uma maior reflexão sobre seu papel social, estendendo seu compromisso com as classes trabalhadoras.

A década de 90 traz poucas mudanças nas questões práticas e tem na extinção da Federação Nacional de Orientadores Educacionais (FENOE), em 1990, entidade criada em Porto Alegre, em 1966, no II Encontro Nacional de Educadores Educacionais, o seu principal evento. Na prática se pretendia fortalecer a categoria no tocante a reivindicações trabalhistas, com a incorporação desta à Confederação Nacional dos Trabalhadores da Educação (CNTE), mas o que houve na realidade, foi um enfraquecimento das associações de classe e uma fragilização da identidade do Orientador Educacional.

Segundo Oliveira (2010) apud Spricigo (2012), os períodos da Orientação Educacional podem ser resumidos da seguinte maneira:

- Período Implementador - compreende o período de 1920 a $194 \mathrm{I}$ - Período em que a Orientação começa a ser implementa no cenário educacional brasileiro, porém ainda com atuação mais direcionada à orientação vocacional.

- Período Institucional - de 1942 a 1960 - caracterizado pela exigência legal da Orientação Educacional nos estabelecimentos de ensino e nos cursos de formação de Orientadores Educacionais.

- Período Transformador - de 1961 a 1970 - a Lei no 4.024/61 determinou as Diretrizes e Bases da Educação (LDB), em que a Orientação Educacional é caracterizada como ação educativa, 
ressaltando a formação do orientador. Para Grinspun (2008), foi por meio dessa Lei que o Orientador Educacional ganhou status de Orientador Educativo e Vocacional, utilizando-se de todos os elementos da escola para desenvolver um trabalho identificador de aptidões individuais.

- Período Disciplinador - 1971 a 1980 - a Orientação Educacional tornou-se obrigatória nas escolas, incluindo o aconselhamento educacional.

- Período Questionador - de 1980 a 1990 - Período no qual houve um movimento que se propôs discutir a Orientação Educacional, tanto do ponto de vista da formação desse profissional, quanto de suas práticas. Esses questionamentos estavam intimamente relacionados com o contexto político da época, em que o país vivenciava um período de grandes transformações sociais e políticas.

- Período Orientador - a partir de 1990 - esse período foi assim denominado pelo fato dos Orientadores Educacionais acreditarem na possibilidade dos serviços de Orientação Educacional atuarem na formação do educando crítico e participativo.

$\mathrm{Na}$ atualidade, com a Lei de Diretrizes e Bases da Educação 9.394/96 que não traz mais a obrigatoriedade da Orientação, o trabalho do Orientador Educacional se caracteriza como um trabalho abrangente, no sentido de sua dimensão pedagógica. Este vai atuar como mediador junto aos demais educadores, atuando não mais de maneira individualizada, mas tendo como enfoque a coletividade, na busca de ações que efetivamente se traduzam em uma educação de qualidade nas escolas. Grispun, 20II, destaca que o papel do Orientador Educacional será ajudar o aluno na formação de uma cidadania crítica, e a escola, na organização e realização de seu projeto pedagógico.

Tendo essa afirmativa como premissa, pretende-se entender como se consolida a atuação do Orientador Educacional em face a esta grande missão, que é a construção do Projeto Político Pedagógico da escola.

\section{Projeto Político Pedagógico}

A sociedade no contexto atual passa por constantes transformações, exigindo das pessoas algumas adaptações às mudanças que surgem, "junto com as transformações vem a crise de paradigmas" (BRANDÃO, 200I, p. 15). De acordo com Gadotti (2000, p. 35):

a crise desses paradigmas também atinge a escola e ela se pergunta sobre si mesma, sobre seu papel como instituição numa sociedade pós-moderna e pós-industrial, caracterizada pela globalização da economia, das comunicaç̃̃es, da educação e da cultura, pelo pluralismo político, pela emergência do poder local.

Para Gadotti (1998), tanto no ambiente escolar como na sociedade de um modo geral, cresce a reivindicação pela participação, autonomia e o desejo de afirmação da singularidade de cada região. 
É baseada nessa afirmação que surge a necessidade de se falar sobre o Projeto Político Pedagógico, por ser o plano da escola, um norte, um rumo a ser tomado, na busca de soluções dos problemas nela encontrados. De acordo com Veiga (2002), um projeto pedagógico de qualidade deve apresentar algumas características como: ser um processo participativo de decisões; preocupar-se em instaurar uma forma de organização do trabalho que desvele os conflitos e contradições; explicitar princípios baseados na autonomia da escola e no estímulo à prática de todos em sua elaboração; conter opções explícitas na direção da superação de problemas existentes; explicitar o compromisso com a formação do cidadão. Desta forma, o Projeto Político Pedagógico deve se constituir na referência norteadora de todos os âmbitos da ação educativa da escola e a sua elaboração exige a participação de todos aqueles que compõem a comunidade escolar para ser expressão viva de um projeto coletivo. Para construir espaços participativos, produzir no coletivo um projeto que reconheça o que a escola é e que aponte o norte do que se propõe a ser, requer método, organização e sistematização.

Contudo, para melhor elucidar a dimensão do Projeto Político Pedagógico da escola, se faz necessário que se tenha claro a definição de cada termo, por isso serão analisados separadamente. A palavra Projeto nos remete à ideia de futuro, tendo como ponto de partida o presente. O termo projeto deriva do latim projectus, que significa algo lançado para frente, a ideia de projeto envolve a antecipação de algo desejável que ainda não foi realizado, traz a ideia de pensar uma realidade que ainda não aconteceu. Mas, e por que Político? Política é uma palavra derivada do grego antigo politeia, que dizia respeito as questões relacionadas à pólis ou cidade-Estado, podendo designar também comunidade, coletividade e outras definições referentes à vida urbana. Dessa forma, é político por considerar a função social da educação e da escola na sociedade e por visualizar a escola como um espaço de formação de cidadãos conscientes e críticos, capazes de atuar individual e coletivamente na sociedade, modificando-a. Nesse sentido o projeto é político por definir o caráter intencional da ação. E Pedagógico? Termo derivado da palavra Pedagogia, que tem sua origem na Grécia antiga, que deriva dos termos paidós, que designa criança e agogé termo grego para condução. No decurso da história do Ocidente, a Pedagogia firmou-se como correlato da educação, é a ciência do ensino. Ao decorrer da História a Pedagogia vai ser entendida como uma prática educativa de cunho social, tendo a sua origem relacionada à origem da própria humanidade. A compreensão do fenômeno educativo e sua intervenção intencional fez surgir um saber específico que modernamente associase ao termo pedagogia. Desta maneira, a expressão pedagógica está relacionada à pedagogia, ou seja, é tudo que se refere aos meios utilizados para que se concretize o ato de ensinar. Portanto, é pedagógico porque define e organiza as atividades e os projetos educativos necessários ao processo de ensino e aprendizagem. 
Libâneo (200I, p. I25) aborda esta temática quando trata da construção de um projeto pedagógico em uma dimensão política e como prática especificamente pedagógica ao destacar que o projeto pedagógico "deve ser compreendido como instrumento e processo de organização das escolas", tendo em conta as características do instituído e do instituinte. Vasconcellos (2005, p. I43) reforça este entendimento, afirmando que o projeto pedagógico:

é um instrumento teórico-metodológico que visa ajudar a enfrentar os desafios do cotidiano da escola, só que de uma forma refletida, consciente, sistematizada, orgânica e, o que é essencial, participativa. E uma metodologia de trabalho que possibilita ressignificar a ação de todos os agentes da instituição.

Veiga (1998) confirma a importância desse projeto ser esse resultado de uma construção coletiva quando diz que:

O projeto pedagógico não é um conjunto de planos e projetos de professores, nem somente um documento que trata das diretrizes pedagógicas da instituição educativa, mas um produto específico que reflete a realidade da escola, situada em um contexto mais amplo que a influência e que pode ser por ela influenciado.

Veiga (2002) reafirma essa ideia ao dizer que o Projeto Político Pedagógico vai além de um simples agrupamento de planos de ensino e de atividades diversas. O projeto pedagógico não é algo que é construído e em seguida arquivado ou encaminhado às autoridades educacionais como prova ou cumprimento de tarefas burocráticas. Ele é construído e vivenciado em todos os momentos, por todos os envolvidos com o processo educativo e acreditando nisso, é que o Projeto Político Pedagógico deve ser construído e executado, envolvendo todos aqueles que fazem parte do processo educativo de forma criativa, participativa e democrática, pois com pequenas mudanças e realizações no interior da escola, é que se torna possível operar grandes transformações, as quais poderão acontecer como resultado de um esforço contínuo, solidário e paciente.

Não se pode desistir do objetivo de atingir uma educação de qualidade e por uma transformação efetiva nas escolas, pois essas devem ser exigências preeminentes e concretas de uma mudança estrutural provocada pela inevitável globalização da economia e das comunicações. Nesta caminhada será importante ressaltar que o Projeto Político Pedagógico busca a organização do trabalho pedagógico da escola na sua totalidade.

A principal possibilidade de construção do projeto político pedagógico passa pela relativa autonomia da escola, de sua capacidade de delinear sua própria identidade. Isto significa resgatar a escola como espaço público, lugar de debate, do diálogo, fundado na reflexão coletiva. (VEIGA, 1998, p.II-35). 
Para Veiga, (1998) "é preciso entender que o Projeto Político Pedagógico da escola dará indicações necessárias à organização do trabalho pedagógico", isso inclui também o trabalho do Orientador Educacional na dinâmica do processo de ensino aprendizagem.

\section{3.r O que diz a LDBEN sobre o Projeto Político Pedagógico}

A Lei de Diretrizes e Base da Educação Nacional no 9394/96, prevê no seu artigo 12, inciso I que os estabelecimentos de ensino, terão a incumbência de elaborar e executar sua proposta pedagógica (art. 12 e 13) plano de trabalho (art. 13) projeto pedagógico (art. 13). Muitas vezes tais nomenclaturas têm provocado certa confusão em termos conceituais e operacionais por parte de muitos profissionais da educação. Para Veiga ( 1995, p. 180)

A proposta pedagógica relaciona-se à organização do trabalho pedagógico da escola, o plano de trabalho está ligado à organização da sala de aula e as outras atividades pedagógicas e administrativas e o projeto pedagógico aponta um rumo, uma direção, um sentido explícito para um compromisso estabelecido coletivamente.

O artigo I3 da LDBEN traz as atribuições dos docentes, sendo que estes têm a incumbência de participar da elaboração da proposta pedagógica de sua escola, bem como elaborar e cumprir o plano de trabalho, segundo a proposta pedagógica do estabelecimento de ensino. O artigo I4 confirma

a necessidade de uma visão democrática na elaboração do Projeto Político Pedagógico, quando afirma 392 que os estabelecimentos de ensino devem primar pela participação dos profissionais da educação na elaboração do Projeto Político Pedagógico da escola, como também a participação das comunidades escolar e local em conselhos escolares ou equivalentes.

A escola deve conceber sua proposta pedagógica ou projeto pedagógico e ter autonomia para executá-lo e avaliá-lo ao assumir uma nova atitude de liderança, no sentido de refletir sobre as finalidades sociais, políticas e culturais. Enfim, essa autonomia deve se pautar em quatro dimensões básicas interligadas entre si: administrativa, jurídica, financeira e pedagógica. E apesar do art. 15 da LDBEN contemplar a autonomia da escola para a gestão participativa, quando determina que os sistemas de ensino deverão assegurar às unidades escolares públicas de educação básica progressivos graus de autonomia pedagógica e administrativa e de gestão financeira, o que se percebe na prática que essa não é ainda a realidade da maioria das escolas públicas brasileiras. Constata-se que a construção do Projeto Político Pedagógico, mesmo sendo oficializado pela LDBEN, a comunidade escolar ainda encontra muitas dificuldades e desafios para que sua elaboração e efetivação ocorra de maneira democrática e participativa.

Para que a construção do Projeto Político Pedagógico seja possível é preciso que os envolvidos no processo educativo percebam a necessidade de um trabalho integrado para a realização de suas 
ações e da luta pelo sucesso da escola, bem como a busca por um padrão de qualidade do ensino e da educação oferecida na escola. "Pensar na educação é pensar na sua relação com a sociedade e a escola, o que não dispensa uma reflexão sobre o homem a ser formado, a cidadania e a consciência crítica" (VEIGA, 1995, p. 13).

Dessa forma, se faz necessário entender o Projeto Político Pedagógico como o resultado de um complexo debate, cuja concepção demanda não só tempo, mas também estudo, reflexão e aprendizagem do trabalho coletivo, contando com a participação da equipe diretiva, professores, pais, alunos e comunidade local, pois todos são atores e sujeitos nesse processo de construção de uma gestão participativa e democrática. Daí a importância de cada unidade escolar construir o seu projeto, considerando suas características próprias, que também é marcada pela diversidade, pelo desenvolvimento e pelas contradições.

\section{O papel do Orientador Educacional na construção do Projeto Político Pedagógico}

O resultado satisfatório de um trabalho realizado pela comunidade escolar depende da ousadia de seus agentes e de cada escola em assumir sua identidade, demonstrando abertura e tentativa de adaptações às mudanças que surgem a cada dia. "O Projeto Pedagógico exige profunda reflexão sobre as finalidades da escola, assim como a explicitação de seu papel social e a clara definição de caminhos" (VEIGA, 1995, p.162). Neste sentido, o Orientador Educacional surge neste cenário, em parceria com a direção da escola, como mediadores, articuladores e interlocutores com os diversos segmentos da comunidade escolar, promovendo espaços de discussão, onde todos os envolvidos no processo educativo tenham a oportunidade de participar da elaboração coletiva e democrática do projeto pedagógico da escola .

Cabe ao Orientador Educacional, profissional componente da equipe pedagógica, mediar o processo de discussão, de elaboração e de construção do Projeto Político Pedagógico nas escolas. Cabe, em síntese, a este profissional da educação a tarefa de conscientizar, estimular, mobilizar, motivar e organizar cada momento de construção do Projeto Político Pedagógico. Ao Orientador Educacional é dado o trabalho de articular e provocar as falas, as opiniões, as ideias e as sugestões. O Projeto Político Pedagógico da escola vai sendo construído e sua forma deve retratar a realidade de cada unidade escolar, e essa ação só será bem-sucedida pela atuação direta do Orientador Educacional.

Dessa forma, o papel do Orientador Educacional na construção do Projeto Político Pedagógico é de suma importância, na articulação do coletivo da escola e é primordial para a 
efetivação da gestão democrática das escolas públicas. Na prática, o Orientador Educacional vai trabalhar articulando junto aos demais educadores, funcionários, pais e alunos promovendo, conjuntamente com a direção, reuniões e grupos de estudo a fim de analisar os problemas e as necessidades da escola, buscando superá-las, de maneira a definir os objetivos, metas, ações e prazos que possam nortear o trabalho pedagógico de determinado período, a fim de garantir a efetivação do processo de ensino e aprendizagem.

O Orientador Educacional pode contribuir, segundo Almeida e Soares (2010), para a elaboração do plano da escola por meio de determinadas ações como: levantar dados para o diagnóstico (dados sobre evasão, aprovação, repetência, estrutura física, recursos disponíveis e necessários, entre outros); subsidiar teoricamente o grupo na análise desses dados, auxiliar na sistematização das ideias propostas para organizar o plano de ação, bem como, articular junto aos colegiados, em especial o Conselho Escolar para que seus membros participem efetivamente da tomada de decisões no processo de construção do Projeto Político Pedagógico.

Cabe ao Orientador Educacional incentivar e participar da constituição do Conselho Escolar, órgão colegiado, representativo de todos os segmentos da comunidade escolar, de natureza deliberativa, consultiva, avaliativa e fiscalizadora, sobre a organização e a realização do trabalho pedagógico e administrativo da instituição escolar. O Conselho Escolar, de acordo com o Estatuto do Conselho Escolar (BRASIL, 2005), é um dos órgãos máximos de direção dos estabelecimentos de ensino. "É um instrumento de gestão colegiada e de participação da comunidade escolar, numa perspectiva de democratização da escola pública” (MAIA e COSTA, 20II, p.86). Para Maia e Costa (20II, p. 87), o Conselho Escolar é constituído pelos seguintes conselheiros dos segmentos da comunidade escolar, sendo eles: diretor, representante da equipe pedagógica, representante do corpo docente, representante dos funcionários administrativos, representante dos funcionários de serviços gerais, representante do corpo discente, representante dos pais de alunos, representante do Grêmio Estudantil, representante dos movimentos sociais organizados da comunidade Associação de Pais, Mestres e Funcionários (APMF), Associação de moradores, igrejas, Unidades de Saúde e outros. Nesse sentido a criação e implementação do conselho escolar permite que diferentes setores da sociedade possam contribuir na gestão da escola de forma democrática e institucionalizada.

É importante ressaltar o papel do Orientador Educacional na constituição do Conselho escolar e na mobilização de seus conselheiros na elaboração do Projeto Político Pedagógico, pois este órgão é constituído por todos os segmentos da comunidade escolar, dessa forma o orientador contribuirá com iniciativas que possibilitem a participação e a democratização do processo de tomada 
de decisões na construção de uma educação de qualidade que contemple os anseios e necessidades da sociedade.

\section{Considerações finais}

$\mathrm{Na}$ busca pela democratização da educação, está comprometida com a justiça e com o desenvolvimento da sociedade, tem-se a possibilidade de concretização desse ideário nas escolas públicas a partir da construção do Projeto Político Pedagógico. Entende-se que o Projeto Político Pedagógico deve contemplar os interesses dos profissionais da educação, assim como os da comunidade escolar com vistas a uma transformação social. Para Grispum (200I) quando a escola trabalha as questões sociais, ela está exercendo o seu real papel pedagógico. O Projeto Político da escola deve refletir o avanço da própria sociedade.

Considerando as discussões levantadas nesse estudo buscou-se compreender o papel do Orientador Educacional na construção do Projeto Político Pedagógico da escola. A partir do estudo realizado percebeu-se que, a função do Orientador Educacional, está longe de ser uma função em desuso, como muitos acreditaram que aconteceria após a reformulação do curso de Pedagogia pelas atuais Diretrizes Curriculares Nacionais (Resolução CNE/CP n. I, de Is de maio de 2006) que torna extinta a formação baseada nas habilitações específicas, o que se percebe, no entanto, é um vasto e 395 não menos importante campo a ser explorado e desvelado por este profissional. O Orientador Educacional é hoje, um dos profissionais essenciais, na construção de uma educação que considera o indivíduo como cidadão capaz de transformar a sociedade em que está inserido. O Orientador Educacional tem um papel primordial na elaboração do Projeto Político Pedagógico, esse longo e complexo caminho que precisa ser percorrido rumo à democratização das escolas públicas. Analisando assim, observa-se que muito se tem que aprender sobre os métodos, a forma de organização e sistematização do trabalho a ser realizado pelos Orientadores Educacionais no âmbito das escolas, pois é através desses espaços de discussões e debates, articulados com o auxílio desse profissional, que de fato será efetivada a gestão democrática nas escolas públicas brasileiras.

Portanto, para que o Projeto Pedagógico da escola seja a concretização da reflexão coletiva da comunidade escolar, a figura do Orientador Educacional é de grande relevância, atuando na articulação com os vários segmentos que compõem a comunidade escolar, incentivando e mobilizando a participação destes nos colegiados, na busca por um ensino de qualidade. Nessa dimensão, o papel do Orientador Educacional é contínuo, dinâmico e permanente, sua atuação contribuirá para a construção coletiva e democrática do Projeto Político Pedagógico e consequente para a democratização de uma educação de qualidade em nosso país. 


\section{REFERÊNCIAS}

ALMEIDA, Claudia Mara de; SOARES, Kátia Cristina Dambiski. Pedagogo escolar: as funções supervisora e orientadora. Curitiba: Ibpex, 2010.

BRANDÃO, Zaia (org.). A crise dos paradigmas e a educação. São Paulo: Cortez, 20or. (Coleção Questões da nossa época, v.35).

BRASIL. MEC. LDBEN - Lei de Diretrizes e Bases da Educação Nacional: no 9.394/96, de 20 de dezembro de 1996. Brasília: A Secretaria, 1996. Disponível em: http://portal.mec.gov.br/seesp/arquivos/pdf/lei9394_ldbni.pdf

Estatuto do Conselho Escolar. Brasília, 2005. Disponível em: $\overline{\mathrm{http}} / /$ /portal.mec.gov.br/seb/arquivos/pdf/Consescol/pr_lond_sttt.pdf

Conselho Nacional de Educação. Conselho Plena. Resolução n. I de I5 de maio de 2006. Institui Diretrizes Curriculares Nacionais para o Curso de Graduação em Pedagogia, licenciatura. Diário Oficial da União, Brasília, DF, i6 mai. 2006. Disponível em: http://portal.mec.gov.br/cne/arquivos/pdf/rcpoi_o6.pdf

GADOTTI, Moacir. Projeto político-pedagógico da escola cidadã. In. Salto Para o futuro: Construindo a escola cidadã, projeto político-pedagógico. Secretaria de Educação a Distância. Brasília: Ministério da Educação e do Desporto, SEED, 1998.

Perspectivas Atuais da Educação. Porto Alegre: Artmed, 2000.

GRINSPUN, Mírian P.S. Zippin. A prática dos Orientadores Educacionais, 4. ed. São Paulo: Cortez, 2001.

A orientação educacional: conflito de paradigmas e alternativas para a escola - 5 ed. - São Paulo: Cortez, 20II.

. Mírian P.S. Zippin (org.). A prática dos orientadores educacionais. 6 ed. Aumentada - São Paulo: Cortez, 2008.

LIBÂNEO, J. C. Organização e Gestão da Escola. Goiânia: Alternativa, 2oor.

MAIA, Benjamin Perez; COSTA, Margarete Terezinha de Andrade. Os desafios e as superações na construção coletiva do projeto político - pedagógico. Curitiba: Ibpex, 20Ir. (Série Processos Educacionais).

SPRICIGO, Fabricio. O Orientador Educacional: atuação, formação profissional e dilemas enfrentados pelo Pedagogo Escolar com o fim das habilitações em Pedagogia. Disponível em: http://periodicos.udesc.br/index.php/linhas/article/view/2419 
VASCONCELLOS, Celso S. Planejamento: Projeto de Ensino-Aprendizagem e Projeto PolíticoPedagógico, $\quad 4^{\text {a }}$ ed. São $\quad$ Paulo: 2005 Libertad,

VEIGA, Ilma Passos Alencastro. Projeto político pedagógico da escola: uma construção possível. Campinas: Papirus, 1995.

Escola: espaço do projeto político-pedagógico. 4 ed. Campinas: Papirus, 1998.

2002.

Projeto Político Pedagógico da escola: uma construção possível. i4 $4^{\underline{a}}$ ed. Campinas: Papirus. 